\title{
Quantifying atmospheric transport, chemistry, and mixing using a new trajectory-box model and a global atmospheric-chemistry GCM
}

\author{
H. Riede, P. Jöckel, and R. Sander \\ Max Planck Institute for Chemistry, Air Chemistry Department, P.O. Box 3060, 55020 Mainz, Germany
}

Received: 22 April 2009 - Published in Geosci. Model Dev. Discuss.: 8 May 2009

Revised: 20 October 2009 - Accepted: 21 October 2009 - Published: 15 December 2009

\begin{abstract}
We present a novel method for the quantification of transport, chemistry, and mixing along atmospheric trajectories based on a consistent model hierarchy. The hierarchy consists of the new atmospheric-chemistry trajectory-box model CAABA/MJT and the three-dimensional (3-D) global ECHAM/MESSy atmospheric-chemistry (EMAC) general circulation model. CAABA/MJT employs the atmospheric box model CAABA in a configuration using the atmosphericchemistry submodel MECCA (M), the photochemistry submodel JVAL (J), and the new trajectory submodel TRAJECT (T), to simulate chemistry along atmospheric trajectories, which are provided offline. With the same chemistry submodels coupled to the 3-D EMAC model and consistent initial conditions and physical parameters, a unique consistency between the two models is achieved. Since only mixing processes within the 3-D model are excluded from the model consistency, comparisons of results from the two models allow to separate and quantify contributions of transport, chemistry, and mixing along the trajectory pathways. Consistency of transport between the trajectory-box model CAABA/MJT and the 3-D EMAC model is achieved via calculation of kinematic trajectories based on 3-D wind fields from EMAC using the trajectory model LAGRANTO. The combination of the trajectory-box model CAABA/MJT and the trajectory model LAGRANTO can be considered as a Lagrangian chemistry-transport model (CTM) moving isolated air parcels. The procedure for obtaining the necessary statistical basis for the quantification method is described as well as the comprehensive diagnostics with respect to chemistry.

The quantification method presented here allows to investigate the characteristics of transport, chemistry, and mixing in a grid-based 3-D model. The analysis of chemical processes within the trajectory-box model CAABA/MJT is easily extendable to include, for example, the impact of
\end{abstract}

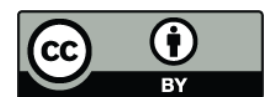

Correspondence to: $\mathrm{H}$. Riede (hella.riede@mpic.de) different transport pathways or of mixing processes onto chemistry. Under certain prerequisites described here, the results can be used to complement observations with detailed information about the history of observed air masses.

\section{Introduction}

Transport, mixing, and chemistry are complex key processes which determine the distribution of chemical species within the atmosphere. Given the concentrations of chemical species observed at a certain point in time and space, the quantification of contributions of the respective processes is often only partially possible. Analyses of the correlations and lifetimes of shorter-lived species can help to assess the effects of mixing and chemistry in some cases ("chemical clocks", e.g., Parrish et al., 2007), but given the complexity of the atmospheric environment, we present a new method to quantify the contributions of transport, mixing and chemistry with a consistent model hierarchy, hereafter termed quantification method.

Several zero- and one-dimensional model types are currently employed in atmospheric research, among them atmospheric-chemistry box models to investigate chemical and photochemical processes at a certain location, e.g., MECCA (Sander et al., 2005), trajectory models to investigate atmospheric transport pathways of air parcels, e.g., LAGRANTO (Wernli and Davies, 1997), TRAJKS (Scheele et al., 1996), and FLEXTRA (Stohl et al., 1995), Lagrangian particle dispersion models, e.g., FLEXPART (Stohl et al., 2005), and combinations thereof, e.g., CLaMS (McKenna et al., 2002), and BRAPHO (Sinnhuber et al., 1999). The specialty of the trajectory-box model CAABA/MJT, presented here for the first time, is its comprehensive and flexible chemical mechanism provided by MECCA and its unique consistency with the global atmospheric-chemistry general circulation model EMAC (Jöckel et al., 2006).

Published by Copernicus Publications on behalf of the European Geosciences Union. 
Table 1. Models and model types involved in the presented method.

\begin{tabular}{|c|c|c|}
\hline Model & Model Type & References \\
\hline \multirow[t]{2}{*}{ EMAC } & atmospheric-chemistry general circulation model ECHAM/MESSy based on ECHAM5; & Jöckel et al. (2005) \\
\hline & submodels: MECCA (chemistry), JVAL (photolysis rate coefficients), and others & Jöckel et al. (2006) \\
\hline \multirow[t]{2}{*}{ CAABA/MJT } & atmospheric-chemistry box model CAABA; & Sander et al. (2005) \\
\hline & submodels: MECCA, JVAL, and TRAJECT (calculations along trajectories) & Sander et al. (2009) \\
\hline LAGRANTO & trajectory model driven by three-dimensional wind fields & Wernli and Davies (1997) \\
\hline
\end{tabular}

A variety of studies so far separated contributions to the concentration of a chemical species in a Eulerian model. The most common techniques define or tag specific tracers, for example a stratospheric ozone tracer (e.g., Kentarchos et al., 2001), or monitor chemistry and fluxes over time for a small region (e.g., Arteta and Cautenet, 2007; Jang et al., 1995).

We consequently further developed the idea of separation to a Lagrangian method by the introduction of the trajectorybox model CAABA/MJT with maximum consistency to the 3-D grid-based EMAC model. Our quantification method follows the air flow in the Lagrangian frame of reference towards an area of interest in the 3-D model (e.g., a measurement site), revealing the complete history of an air mass time step by time step or integrated over time.

In contrast to other methods, in which Lagrangian and Eulerian models are coupled online to treat various processes differently (e.g., Stenke et al., 2009; Manonom, 2000), the coupling between the trajectory-box model CAABA/MJT and the 3-D model EMAC is offline and for the purpose of interpretation of 3-D model data. The trajectory-box model is applied to trajectories calculated by LAGRANTO based on EMAC 3-D wind fields. LAGRANTO is a kinematic trajectory model (Wernli and Davies, 1997). The models used in the present study and their types are summarised in Table 1, their spatial regimes are shown in Fig. 1. The trajectories are clustered based on starting-point similarity and only the time median trajectories of these clusters are used for CAABA/MJT simulations. The sizes of the clusters they represent are used to estimate the representativeness of results.

If results are intended to be used for the interpretation of observations, model-observation agreement is a prerequisite. Additionally, equivalent trajectories based on forecast or reanalysis data are used for a comparison of transport.

\section{Methodology}

\subsection{Quantification using a model hierarchy}

The 3-D EMAC model and the atmospheric-chemistry box model CAABA (Sander et al., 2009) were both developed within the MESSy framework (Jöckel et al., 2005), which aims to define separate independent submodels for different

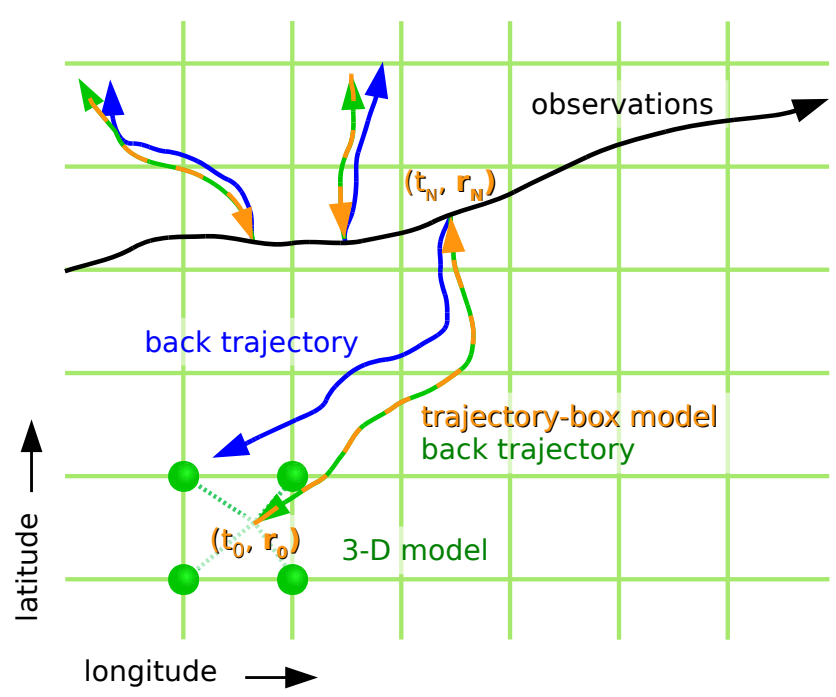

Fig. 1. The applied models, observations, and their spatial regimes are shown. Observations are collected, in this case on a moving platform (black). Back trajectories are calculated as is often routine in campaign support (blue). In our approach, back trajectories are based on wind fields from the 3-D model (green) and chemistry is calculated forward in time (from $t_{0}$ to $t_{N}$ ) along the trajectories with a trajectory-box model (orange). Mixing ratios at the start of a trajectory $\left(t_{0}, \boldsymbol{r}_{\mathbf{0}}\right)$ are taken from the 3 -D model (green grid). The initial values are determined by interpolation (dotted green lines) between adjacent values (green dots) on the 3-D model grid.

Earth system processes, and which allows flexible coupling of these submodels to various base models. This is shown here for the submodels MECCA and JVAL being coupled to CAABA and EMAC as base models (Fig. 2).

The trajectory-box model setup presented in this publication employs CAABA as base model and uses three submodels: the submodel MECCA to simulate atmospheric chemistry, the submodel JVAL to determine photolysis rate coefficients, and the new submodel TRAJECT for the processing and interpolation of trajectory information. This is the combination of submodels presently referenced as CAABA/MJT. For the 3-D EMAC model simulation, the same submodels MECCA and JVAL were used in the same configurations. Together with the transfer of initial conditions and physical 


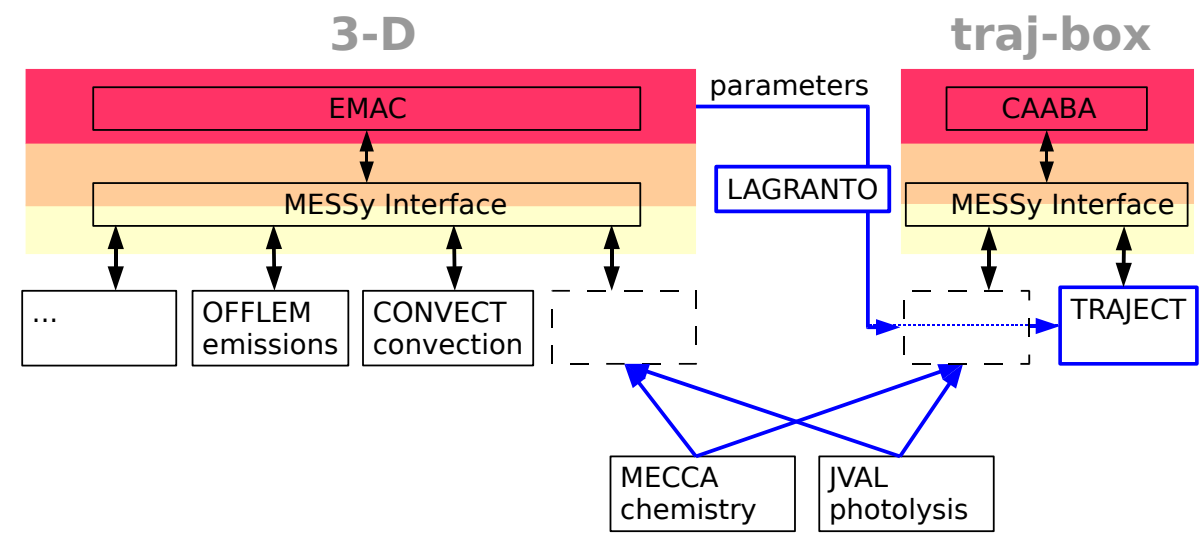

Fig. 2. Schematic structure of the trajectory-box model CAABA/MJT and the global 3-D model EMAC. Both models feature a layered structure (MESSy) from the base model layer via interface layers down to the submodel layer, in which different submodels describe different physical and chemical processes. The trajectory model LAGRANTO calculates trajectories based on EMAC wind fields. Consistency of CAABA/MJT with EMAC is achieved by two means: the same submodels MECCA and JVAL are used in both models, and trajectory simulation parameters and initial conditions from EMAC are transferred to the respective submodels (blue arrows).

parameters from the 3-D model to the trajectory-box model, an exceptionally high consistency between the two model setups is achieved, so that CAABA/MJT can emulate the chemistry that takes place in EMAC. As initial conditions, chemical tracer mixing ratios at the beginning of the EMACbased trajectory are sampled from EMAC tracer fields. The parameters include temperature, moisture, pressure (influencing chemistry), and longitude, latitude, height, and photolysis rate coefficients (influencing photochemistry). They are sampled from EMAC along the complete trajectory. Trajectories are based on the 3-D wind fields from EMAC to ensure consistency in transport between trajectory-box model and global model.

In the following paragraphs, we will explain how the intramodel consistency is used to quantify individual atmospheric processes. We use combinations and comparisons of results from $\mathrm{CAABA} / \mathrm{MJT}$ and from EMAC to determine the contributions of mixing, chemistry and transport along the trajectories, which are provided offline.

The quantification along a trajectory is individual for each tracer $\mathrm{M}$ and also dependent on the chosen trajectory backward travel time $\Delta t$. The mixing ratio $\mu_{M}$ initialised at the beginning of a trajectory, interpolated from EMAC gridbased results at the corresponding position in time $\left(t=t_{0}\right)$ and space $\left(\boldsymbol{r}=\boldsymbol{r}_{\mathbf{0}}=\left(x_{0}, y_{0}, z_{0}\right)\right)$, defines the influence of undis-

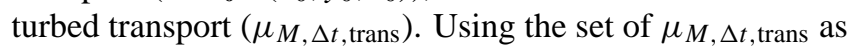
initial condition, the system of chemical kinetic equations is solved within CAABA/MJT forward in time along the trajectory. The differences of mixing ratios between start $\left(t_{0}\right)$ and end $\left(t_{N}\right)$ of the trajectory define the contribution of chemistry $\left(\Delta \mu_{M}, \Delta t\right.$,chem $)$. Finally, due to the high consistency between the trajectory-box model CAABA/MJT and the 3-D EMAC model, it is possible to attribute differences in tracer mixing ratios between the two models at the end of a trajectory to mixing, the only fundamental difference $\left(\Delta \mu_{M}, \Delta t\right.$, mix $)$. Figures 3 and 4 , and the following equations summarise the above description; CAABA/MJT is abbreviated as C, EMAC as E:

$$
\begin{gathered}
\mu_{M, \Delta t, \text { trans }}=\mu_{M, \Delta t}\left(\mathrm{E}\left(t_{0}, \boldsymbol{r}_{\mathbf{0}}\right)\right)=\mu_{M, \Delta t}\left(\mathrm{C}\left(t_{0}\right)\right) \\
\Delta \mu_{M, \Delta t, \text { chem }}=\mu_{M, \Delta t}\left(\mathrm{C}\left(t_{N}\right)\right)-\mu_{M, \Delta t}\left(\mathrm{C}\left(t_{0}\right)\right) \\
\Delta \mu_{M, \Delta t, \text { mix }}=\mu_{M}\left(\mathrm{E}\left(t_{N}, \boldsymbol{r}_{N}\right)\right)-\mu_{M, \Delta t}\left(\mathrm{C}\left(t_{N}\right)\right) .
\end{gathered}
$$

Note that the dependence on $\Delta t$ in the equations presented here is specific for backward trajectories. In the case of forward trajectories, $\mu_{M}\left(\mathrm{E}\left(t_{N}, \boldsymbol{r}_{N}\right)\right)$ instead of $\mu_{M}\left(\mathrm{E}\left(t_{0}, \boldsymbol{r}_{\mathbf{0}}\right)\right)$ would be dependent on the trajectory travel time.

The definition of transport here is thus equivalent to the idea of a variety of passive tracers advected within an isolated air parcel. Within the trajectory-box model CAABA/MJT, tracers are now chemically active, but still move within an isolated parcel. EMAC in turn treats chemistry equivalent to CAABA/MJT, but also considers physical exchange processes between grid boxes, for example diffusion and convection.

So far in this approach, the contributions of transport, chemistry, and mixing to the mixing ratio of a certain tracer $\mathrm{M}$ were defined within the model hierarchy. The information gained with this approach is available at any point integrated forward in time from the starting point defined by the trajectory backward travel time $\Delta t=t_{N}-t_{0}$ (see left part of Fig. 4). If a comprehensive set of trajectories along a series of observations is evaluated, it is useful to consider the integrated contributions at the sites of observation, i.e. the start of the back trajectory and the end of the trajectory-box model calculation. The right part of Fig. 4 shows the integrated contributions for a single trajectory. A change in the 


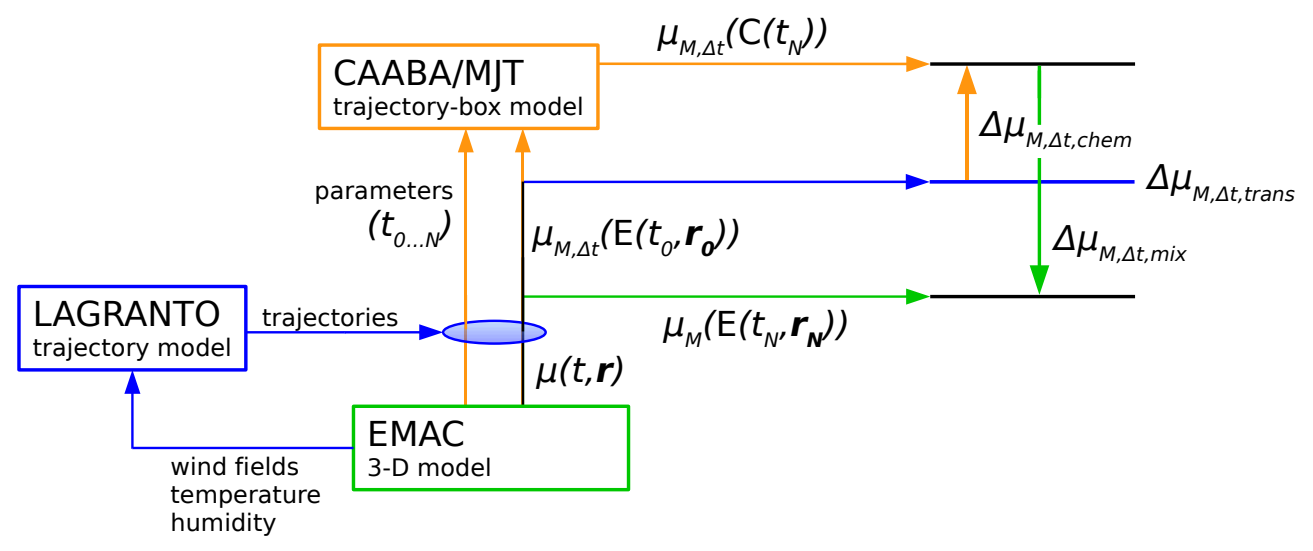

Fig. 3. Schematic flow of data between models, and combinations of data for the quantification. The trajectories calculated by LAGRANTO based on EMAC data serve as a filter for data passed on to the trajectory-box model (blue ellipse). Parameters for the trajectory-box model simulation are thus selected from the vast set of EMAC 3-D data as well as the initial mixing ratio $\mu$ for each tracer $\mathrm{M}$ at the beginning $\left(t_{0}, \boldsymbol{r}_{\mathbf{0}}\right)$ and at at the end of the trajectory $\left(t_{N}, r_{N}\right)$. After the trajectory-box model simulation, data is recombined to yield an absolute contribution of transport (blue) and relative terms for chemistry (orange) and mixing (green).

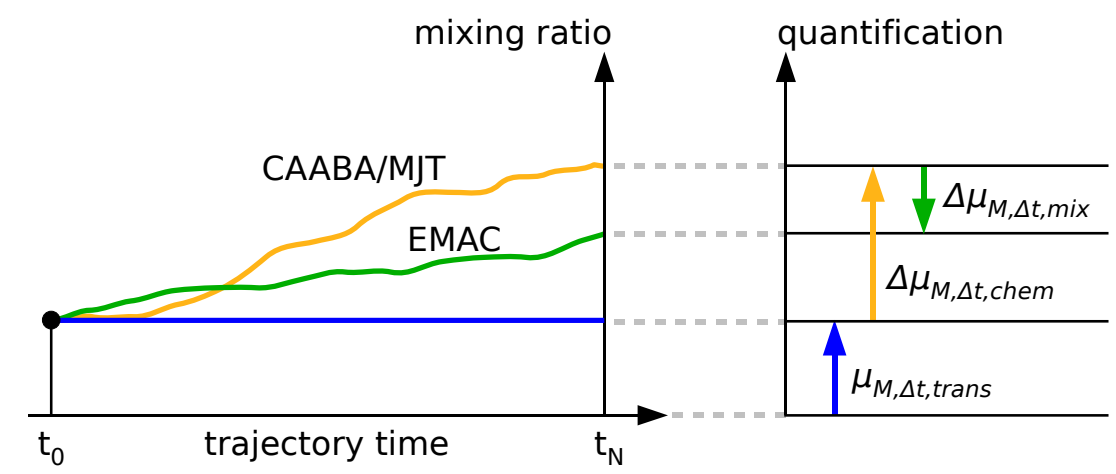

Fig. 4. Separation and quantification of contributions for a single trajectory is depicted schematically. The time evolution of a mixing ratio for a certain species in the two models (left) and the subsequent translation into the separate contributions of transport, mixing, and chemistry (right) are shown. In the particular example depicted here, chemical production along the trajectory is much larger than the initial value that would have been measured with transport alone, but is partly compensated by mixing.

backward travel time, in contrast, requires a new trajectorybox model calculation and leads to a systematic change in contributions as the chemistry contribution is dependent on the initial condition, i.e., the transport contribution. Examining integrated contributions with varying the backward travel time serves to identify where along a trajectory mixing is important and how chemistry changed due to mixing events without having to look at the evolution along single trajectories (see Sect. 2.4).

\subsection{Statistical basis for quantification results}

To ensure a statistical basis for results from the trajectorybox model, the trajectories are grouped into trajectory clusters. The simple grouping method applied here uses a certain absolute horizontal transport deviation and a certain ratio of pressures of the starting points as thresholds between sepa- rate clusters (see also Sect. 4). Of these clusters, a trajectory in the time mean is kept as a representative to be used in the CAABA/MJT trajectory-box model simulations and for further analysis, while the overall number of trajectories within the cluster provides its statistical weight. The more statistical weight a trajectory has, the more representative are the quantificaton results which are based upon it. If this simple starting point similarity is appropriate to separate distinct transport pathways can be tested (Sect. 2.3).

\subsection{Analysis of transport}

If backward trajectories are analysed, systematic sensitivity tests can be conducted by variation of the backward time of the trajectories. The decrease or increase of trajectory clusters formed as trajectories are regrouped is used to detect convergence or divergence of transport, respectively. In 
a)

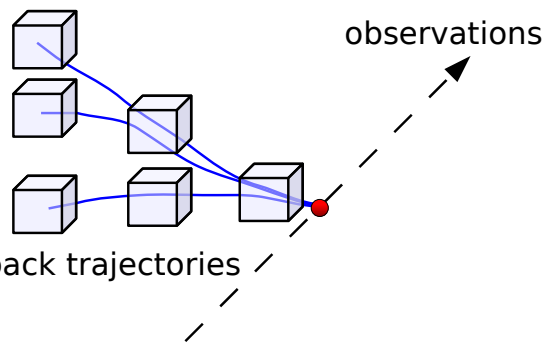

b)

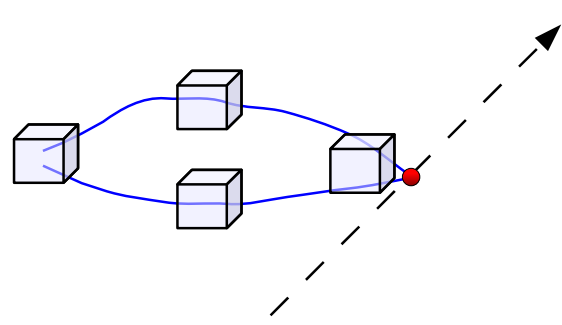

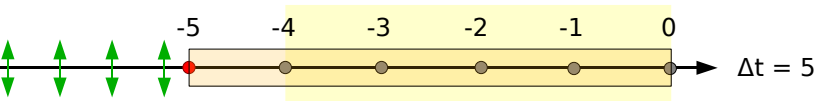

mixing + chemistry chemistry

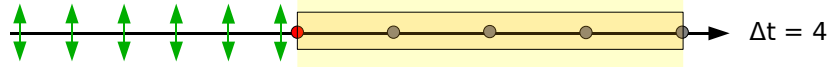

Fig. 6. Extracting information about the influence of mixing onto chemistry is possible through variation of the backward travel time. Red points mark the start of a trajectory-box model simulation. After the start of the chemistry calculation, there is no material exchange with the environment. The difference $\Delta \mu_{M, 4, \text { chem }}-\Delta \mu_{M, 5, \text { chem for the last four days quantifies the }}$ chemistry contribution due to mixing between day -4 and -5 for the four-day simulation.

Since quantification is not only a function of the tracer, but also of the trajectory time interval simulated, contributions of transport, chemistry, and mixing are transformed with the reduction of backward travel time $\Delta t$. In general, the reduction of backward time scans which process is important at what time in the history of air masses. With a shift of the starting point of the simulation closer to the end of the trajectory, a former contribution of mixing at that point and time will turn into a contribution of transport. Formerly secondary effects of chemistry from mixing, in turn, are now explicitly treated in CAABA/MJT. Now, further investigation of the chemistry formerly "hidden" in the mixing term can take place. For example, comparing a trajectory-box model simulation of four days with the last four days of a five-day simulation along the same trajectory reveals the effect of mixing between day four and day five onto chemistry during the last four days (Fig. 6). In Sect. 4.3 of the application example, the quantification of the impact of mixing onto subsequent chemistry is shown for selected species.

A detailed analysis of chemical reactions is outlined in the model description of CAABA in Sect. 3.1 and exemplarily shown in the application (see Fig. 15).

\subsection{Transferability of the quantification results to observations}

Is the quantification method valid in reality, i.e. can we interpret field measurements with it? As a basis for the transfer of results, a comparison between observational data and data from the 3-D model is mandatory. Only if the general features in the measurement series and in the corresponding data sampled from the 3-D model are in agreement, subsequent analysis using the model hierarchy is meaningful for the interpretation of the selected campaign data.

Furthermore, consistency of transport is investigated. In addition to the trajectories based on wind fields from the 3-D model, sets of trajectories based on wind fields from a 
forecast or reanalysis model (e.g., ECMWF ${ }^{1}, \mathrm{NCEP}^{2}$ ) are calculated. Trajectories are grouped as described in Sect. 2.2. Representative trajectories of the 3-D model and the forecast or reanalysis model are then compared. Common methods of comparison between trajectories include the absolute horizontal and vertical transport deviation between single trajectory points and mean errors between whole trajectories, as applied for instance in Stohl et al. (2001) and Knudsen et al. (2001). For a general discussion of trajectory uncertainties, see for example Stohl (1998).

\section{Model descriptions}

\subsection{CAABA box model and submodels}

$C A A B A, C$ hemistry As A Box model Application (Sander et al., 2009), is an atmospheric chemistry box model developed within the MESSy framework (Jöckel et al., 2005). In this publication, it is used as base model to which submodels are coupled via the standardised MESSy interface, for example the submodels MECCA for atmospheric chemistry, or JVAL for photolysis rate coefficients. For the present study, the submodels simulating sedimentation and deposition are switched off so that CAABA/MJT simulates only kinetic processes.

MECCA, the Module Efficiently Calculating the Chemistry of the Atmosphere (Sander et al., 2005), simulates tropospheric and stratospheric chemistry and photochemistry. The KPP (Kinetic Pre-Processor) software (Sandu and Sander, 2006) is used for the integration of the set of stiff differential equations describing chemistry. Besides the pre-selected chemical mechanisms provided, it is possible to customise the mechanism by simple boolean commands. The mechanism for the present study comprises 385 gas phase species, 180 gas phase reactions, and 60 photolysis reactions. Only the mixing ratios of nitrogen $\left(\mathrm{N}_{2}\right)$, oxygen $\left(\mathrm{O}_{2}\right)$, and carbon dioxide $\left(\mathrm{CO}_{2}\right)$ are fixed during the simulation. In consistency with the application of MECCA within EMAC during the S1 simulation (see Sect. 3.2), aerosol chemistry as described in Kerkweg et al. (2007) was switched off. To simplify the application case study presented in Sect. 4, heterogeneous reactions were neglected in the present box model setup.

Besides the standard chemistry simulation, the chemistry submodel MECCA provides information for a more detailed analysis of chemical processes. The inclusion of customised diagnostic tracers (e.g., "loss of ozone") into the chemical mechanism allows to monitor the overturn of certain species or reaction systems. With all the chemical equations and reaction rates available, a detailed listing of positive and negative contributions of individual reactions to a certain species is possible. This can be calculated for a time period, e.g., the whole trajectory time, or single integration time steps.

\footnotetext{
${ }^{1}$ http://www.ecmwf.int/

${ }^{2}$ http://www.ncep.noaa.gov/
}

The JVAL submodel is employed for fast online calculation of photolysis rate coefficients accounting for climatological aerosol as well as cloud water content, cloud cover, and ozone either provided by the base model or by a climatology (Landgraf and Crutzen, 1998). A delta-two-stream method is used for eight spectral intervals in the UV and visible together with pre-calculated effective cross-sections, partly temperature and pressure dependent, for more than 50 tropospheric and stratospheric species. From a static 19-layer array with typical 3-D model values for the vertical ozone column, values are extracted based on the model pressure. Only the photolysis rates for species present in the chosen chemical mechanism are calculated. In the present setup, cloud fraction and cloud water content are set to zero in the trajctory-box model to simplify the sample application. A compensation for this neglect is described at the end of the next paragraph.

TRAJECT is the new trajectory submodel in CAABA, which provides the infrastructure to change physical parameters such as longitude, latitude, pressure, temperature, relative humidity, and photolysis rate coefficients between consecutive time steps of the chemical kinetics simulation. The chemistry in CAABA/MJT should perfectly match the chemistry in EMAC, which is easy to achieve for the chemical mechanism using MECCA in both models. Photochemistry is also treated consistently via JVAL. However, there are influences from the three-dimensional environment onto photochemistry in EMAC, for example by aerosol or clouds, which cannot be described in a (trajectory-)box model. To improve consistency between both models with respect to these 3-D effects, the parameters for CAABA/MJT simulations are extended to include photolysis rates sampled from the 3-D model. They transmit information about cloud cover and aerosol optical density to the box model framework. To limit the amount of data for the example presented later, we used only the photolysis rate of $\mathrm{NO}_{2}$ from EMAC. The ratio between the respective $\mathrm{NO}_{2}$ photolysis rates from EMAC and from CAABA/MJT at each time step is applied as a scaling factor to all other photolysis rates in CAABA/MJT. Note, however, that there is no method-inherent limitation on the number of parameters sampled from the 3-D model.

A trajectory consists of a number of individual waypoints. The minimum number of trajectory waypoints to be provided is two. An external file in netCDF ${ }^{3}$ format provides the discretised parameters on these waypoints to the trajectory-box model as part of the offline input. For the waypoints, there is no requirement for equidistance in time or space. If trajectory waypoints do not coincide with the fixed CAABA integration time steps, additional time steps are inserted around the trajectory point so that the regular time stepping as well as the trajectory waypoints are present in the trajectory-box model output (Fig. 7). Between trajectory waypoints, linear interpolation is applied to the physical parameters.

\footnotetext{
${ }^{3}$ http://www.unidata.ucar.edu/software/netcdf/
} 


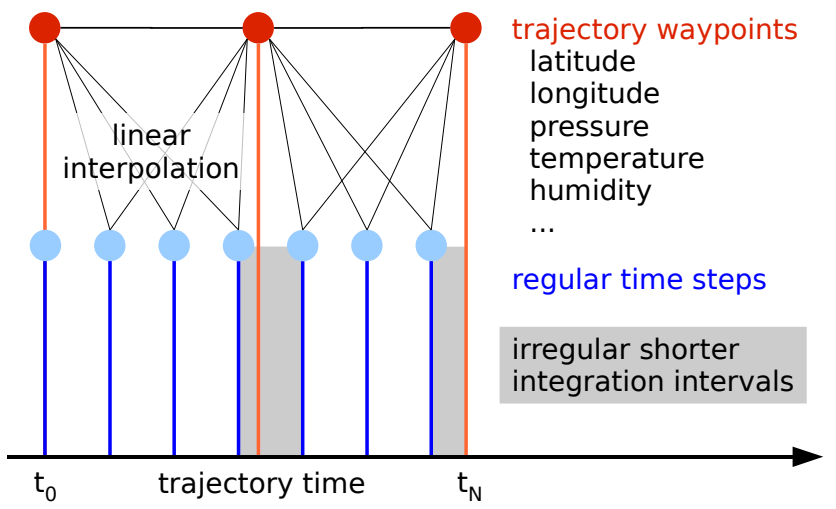

Fig. 7. Time stepping scheme for a single trajectory showing the trajectory waypoints prescribing physical parameters (top, red), and the regular time steps, typically $15 \mathrm{~min}$ intervals (middle, blue). Regular integration points that do not coincide with a trajectory point are evaluated using linear interpolation between the trajectory points. Trajectory waypoints are always evaluated independent of the regular time stepping so that smaller time steps are inserted around trajectory points that do not coincide with a regular integration point (bottom, grey shade).

By default, the model simulation time is defined by the length of the trajectory. However, it is possible via two namelist parameters to modify the time period and the start of the simulation so that an arbitrary section along the trajectory can be chosen, independent of waypoints or time step interval. Figure 8 depicts the applied operator splitting for a trajectory with three trajectory waypoints, of which only an inner section is simulated.

\subsection{EMAC S1 simulation}

The ECHAM/MESSy Atmospheric Chemistry (EMAC) model is a numerical chemistry and climate software that includes submodels describing tropospheric and middle atmosphere processes and their interactions with oceans, land and human influences (Jöckel et al., 2006). It uses the first version of the Modular Earth Submodel System (MESSy1) to link multi-institutional computer codes. The core atmospheric model is the 5th generation European Centre Hamburg general circulation model (ECHAM5, Roeckner et al., 2006). The results from the evaluation reference simulation S1 (Jöckel et al., 2006) used in the present publication were obtained with the ECHAM5 version 5.3.01 and MESSy version 1.0 in the T42L90MA resolution, i.e. with a spherical truncation of T42 (corresponding to a quadratic Gaussian grid of approximately 2.8 by 2.8 degrees in latitude and longitude) and with 90 vertical hybrid pressure levels up to $0.01 \mathrm{hPa}$. The applied model setup comprised the submodels as described in Jöckel et al. (2006), among them MECCA and JVAL. Online emissions include DMS from the oceans, NO from soils and isoprene from plants. Offline emissions

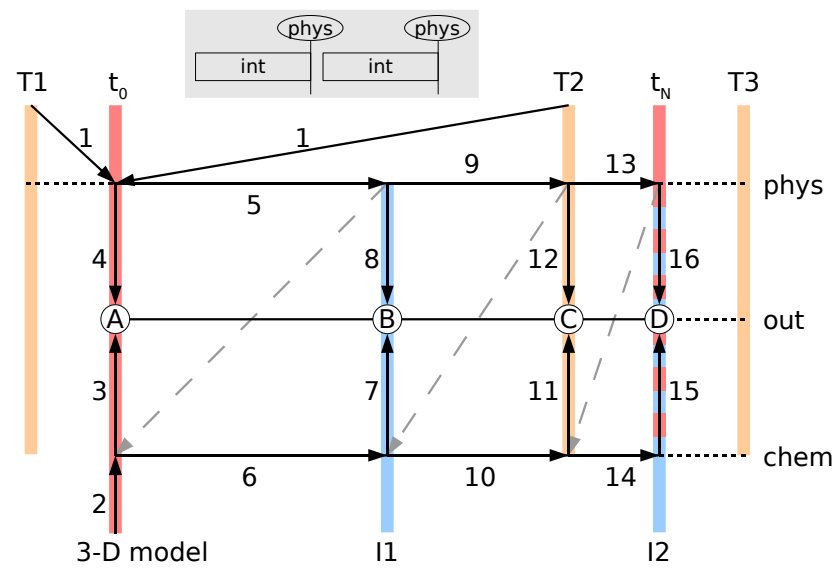

Fig. 8. Operator splitting scheme for the calculation of an inner section of a trajectory with three waypoints. Physical parameters are shown in the upper (phys), chemistry progress in the lower (chem), and output intervals in the middle string (out). Initial physical parameters are linearly interpolated between the first (T1) and the second (T2) trajectory waypoint (1). Chemistry is initialised with mixing ratios from the 3 -D model (2). These values are written to output $(3,4, \mathrm{~A})$. The physical parameters are updated (5) before integration of the chemistry equations takes place (6) and results are output (7, $8, \mathrm{~B})$. Sequence $5-8$ is repeated $(9-12,13-16)$ on trajectory waypoints (T2) and regular integration points (I1, I2) as shown in Fig. 7 until the defined end of the calculation is reached. In the shaded box, the very simplified scheme shows that each integration step is performed with the parameters from the end of the corresponding time interval.

are based on the $\operatorname{EDGAR}^{4}$ emissions database with incorporated fire emissions based on the Global Fire Emissions Database (GFED) for the year 2000. A Newtonian relaxation technique was applied in the free tropospheric part to weakly nudge the model towards the analysed ECMWF meteorology. Thus, direct comparisons between model results and observations become feasible.

\section{Application example}

\subsection{Regional meteorology}

As an example, the quantification method is applied to a fiveday back trajectory with hourly waypoints calculated with the 3-D trajectory model LAGRANTO (Wernli and Davies, 1997) driven by EMAC wind fields. The trajectory was chosen from among the 21 trajectories depicted in Fig. 9, each representative for a cluster of trajectories as described in Sect. 2.2. The trajectories show an anticyclonic movement of air masses above Africa in January 2000, with a common submergence zone at $10-15^{\circ} \mathrm{N}$. The subsequent fast westerly

\footnotetext{
${ }^{4}$ http://www.mnp.nl/edgar/model/v32ft2000edgar/
} 


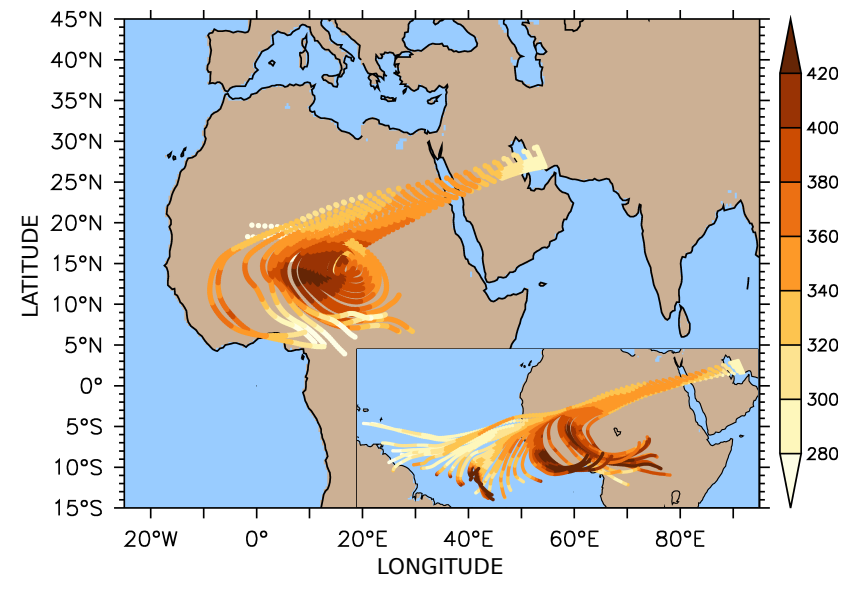

Fig. 9. Five-day back trajectories from the sub-Sahel region in January 2000 based on EMAC wind fields. Pressure altitude in $\mathrm{hPa}$ is indicated by colour. The inset shows the same five-day back trajectories based on ECMWF wind fields. Note that each of the trajectories shown represents a cluster of 3-35 (EMAC) or 1-92 (ECMWF) similar trajectories.

Table 2. Backward travel time of trajectories and the respective numbers of trajectory clusters, i.e. representative trajectories. The third row contains the remaining number of trajectories divided by the number of trajectories in the 5-day reference in percent. The relative percent change for each 1-day reduction is reported in the last row.

\begin{tabular}{lrrrrr}
\hline backward (days) & 5 & 4 & 3 & 2 & 1 \\
\hline number of clusters & 21 & 13 & 10 & 9 & 6 \\
remainder (\%) & 100 & 62 & 48 & 43 & 29 \\
relative \% change & & -38 & -23 & -10 & -33 \\
\hline
\end{tabular}

movement is a typical climatological feature (see ECMWF ERA-40 Atlas ${ }^{5}$ ). A comparison with respective trajectories based on ECMWF wind fields (inset of Fig. 9) shows the same anticyclonic movement with a different shape and partly different and lower source regions. The transport pathways crossing the tropical Atlantic are also observed for EMAC trajectories at a later time, approximately shifted by 15 to $30 \mathrm{~min}$ (not shown).

The coherence of transport to a certain region and time interval is investigated by reducing the backward travel time of the corresponding trajectories. If the thresholds for grouping the trajectories into clusters remain constant, reducing the travel time usually reduces the number of representative trajectories necessary to describe all distinct transport pathways. The threshold values used here are adopted from the typical grid resolution of the 3-D EMAC model, i.e. 2.8 degrees in longitude and latitude, and a ratio of 1.1

\footnotetext{
${ }^{5}$ http://www.ecmwf.int/research/era/ERA-40_Atlas/
}

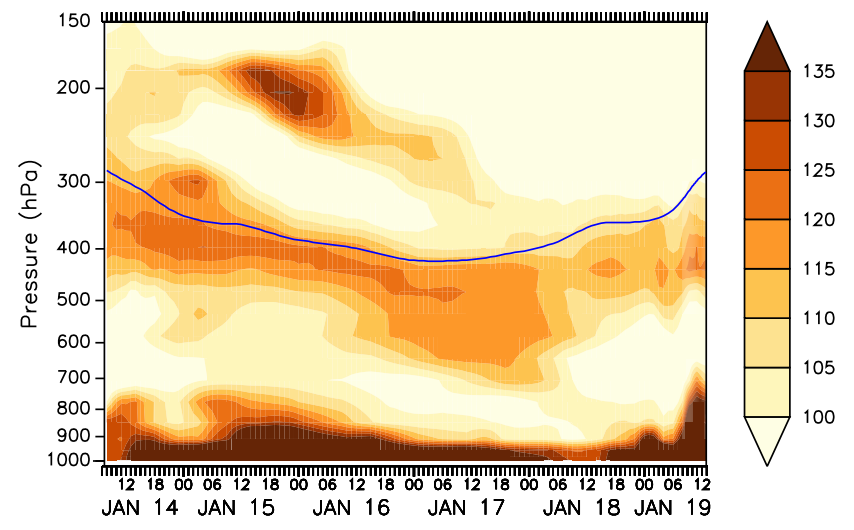

Fig. 10. Vertical cross section of CO mixing ratios (nmol/mol) from EMAC along the trajectory path (blue). Biomass burning activity in the sub-Sahel zone during boreal winter causes high $\mathrm{CO}$ gradients near the surface and $\mathrm{CO}$ plumes at higher altitudes. The tropopause lies above $150 \mathrm{hPa}$ and is not shown.

between pressure values. As the travel time is successively reduced from five days to one day in one-day steps, less clusters with more trajectories in each are formed. The number of representative trajectories in this example is reduced by 38 , 23,10 , and $33 \%$, respectively (Table 2). This corresponds to the visual impression of Fig. 9: after an incoherent start, the trajectories converge to form the anticyclonic movement, in which less convergence and divergence take place. This is the first important reduction of representative trajectories by 38 percent. For the last day of fast coherent travel towards the Persian Gulf, there is a second important reduction of 33 percent. The monotonous decrease of representative trajectories indicates that the absolute horizontal transport deviation is a reasonable proxy to describe distinct transport pathways (see Sect. 2.2).

The representative trajectory selected for the sample simulation travels from approximately $290 \mathrm{hPa}(\sim 10 \mathrm{~km}$ altitude $)$ in the upper troposphere down to below $400 \mathrm{hPa}(\sim 7 \mathrm{~km})$ in the free troposphere above the sub-Sahel zone and back up to an airborne observation platform above the Persian Gulf at about $290 \mathrm{hPa}$. The respective vertical cross section of EMAC carbon monoxide (CO) mixing ratios (Fig. 10) shows strong gradients from the boundary layer upwards and plume structures. This is consistent with the observation of excessive biomass burning activities in the sub-Sahel during boreal winter (Barbosa et al., 1999). The chosen trajectory is purely tropospheric, the 3-D model tropopause being at higher altitudes below $150 \mathrm{hPa}$, and crosses a CO plume layer on its way.

\subsection{Quantification}

If we examine the full five-day trajectory, chemical species are initialised with mixing ratios interpolated from EMAC at the starting point of the trajectory five days prior to the 


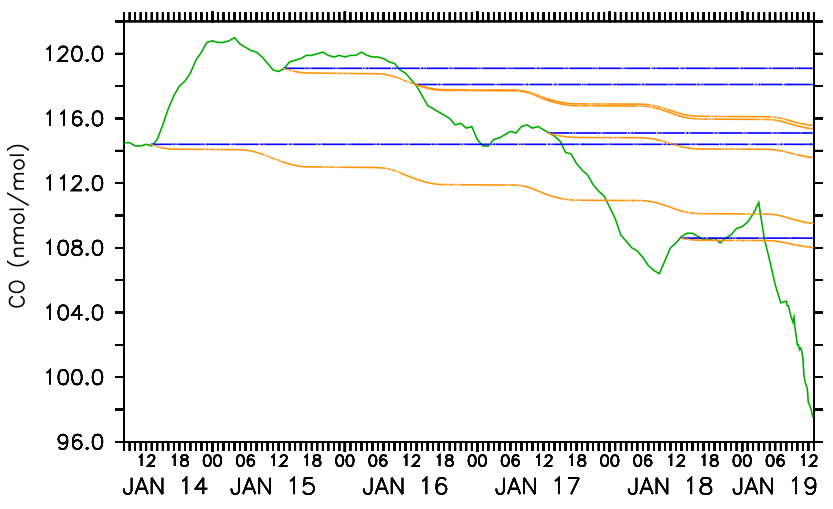

Fig. 11. Application example for the left part of Fig. 4. From the time series of $\mathrm{CO}$ mixing ratios sampled from EMAC (green solid line), the initial mixing ratio for the trajectory-box model is chosen five days prior to observations (leftmost blue dashed line). The subsequent chemical evolution calculated by CAABA/MJT is shown as orange dash-dotted line. The results for possible shorter backward travel times are shown as well.

point of observation. The time series of $\mathrm{CO}$ mixing ratios along the trajectory path sampled from EMAC, various $\mathrm{CO}$ initialisation levels for CAABA/MJT, and the corresponding chemical evolutions of $\mathrm{CO}$ within CAABA/MJT are depicted in Fig. 11. For the five-day analysis, the comparatively low effective mixing ratio of $\mathrm{CO}$ in EMAC at the end of the trajectory is deconvolved into a small and steady negative contribution of chemistry and a strong dilutive mixing effect following the initially strong positive contribution of mixing. Whereas mixing processes play an important role all along the trajectory, the different initial mixing ratios of $\mathrm{CO}$ for different backward travel times of the trajectory do not have a discernible impact onto $\mathrm{CO}$ chemistry.

Applying Eqs. (1-3) to the mixing ratios of $\mathrm{CO}$ and several other chemical species over the whole period of five days yields the net contributions presented in Fig. 12. This integration of information is necessary in order to evaluate comprehensive sets of trajectories, which in turn is mandatory for a statistical evaluation. However, as shown in Fig. 11, the detailed information for a closer analysis of single trajectories is available at any point of a trajectory calculation.

The biomass burning activities mentioned in Sect. 4.1 are reflected in the elevated initialisation mixing ratios for typical biomass burning tracers such as carbon monoxide. Due to the relatively long lifetime in the upper troposphere, chemistry contributions are relatively small, where ozone is the only tracer shown to be chemically produced. There is a negative contribution of mixing to all the tracers, which takes place due to local mixing ratio maxima from biomass burning emissions at the beginning of the trajectory.

\subsection{Further analysis of chemistry}

When analysing atmospheric chemistry involving potential catalysts, such as nitrogen oxides for ozone production, it is especially interesting to assess the chemistry, which occurs due to mixing along a trajectory. Figure 13 shows how the chemistry contribution presented in Fig. 12 changes when reducing the backward travel time of the trajectory (see Sect. 2.4 for theory). Note that even though the simulation time decreases linearly, the chemistry contributions for $\mathrm{NO}_{\mathrm{x}}$ and formaldehyde do not decrease monotonously, a sign for the influence of mixing onto chemistry or the chemical evolution during transport? A comparison between column pairs for one species reveals that for the present example, mixing processes one day prior to the start of the trajectorybox model simulation have a dampening effect onto the chemistry of the selected species. Consequently, the percent contributions for chemistry effected by mixing are negative. A different situation would be expected for instance during a photo smog event, where mixing processes bring reactants and precursors together. Thus, the chemistry contributions for $\mathrm{NO}_{\mathrm{x}}$ and formaldehyde in this example occur mostly due to chemical processes within the isolated air parcel, not due to mixing on the way.

Figure 13c depicts as an example the mixing contributions one day prior to the chemistry simulations for the same selected tracers. The positive mixing contribution for $\mathrm{CO}$ between days 5 and 4 , for example, does not seem to impact its net chemical loss.

The robustness of the chemistry quantification with respect to the transport pathway can be assessed via ensemble plots as presented in Fig. 14. They show the chemical evolution along EMAC and along ECMWF trajectories from the same start time interval. As expected for carbon monoxide, being a longer-lived tracer with respect to the trajectory travel time of five days, the influence of transport, i.e. initialisation, is much higher than the impact of chemistry, which shows a uniform decline. For the shorter-lived nitrogen oxides $\left(\mathrm{NO}_{\mathrm{x}}\right)$, much more variability due to chemistry is observed. The trajectories with high initial $\mathrm{NO}_{\mathrm{x}}$ mixing ratios in the ECMWF ensemble compared to the EMAC ensemble originate from Suriname and the north-east coast of Brazil and show a different chemical evolution crossing the Atlantic. Consequently, the chemical evolution in similar situations has to be assessed in shorter time intervals, taking the dynamic situation into account. It needs to be stressed that mixing is exclusively defined within the model hierarchy, i.e. there is no comparable equivalent ECMWF entity to compare it to. Therefore, a similar uncertainty analysis for chemistry with respect to mixing is not possible.

Further analysis of chemical processes as outlined in the model description for MECCA (Sect. 3.1) is depicted in Fig. 15. Chemical contributions to production and loss of formaldehyde and carbon monoxide are evaluated based on the chemical mechanism and the reaction rates. Along the 


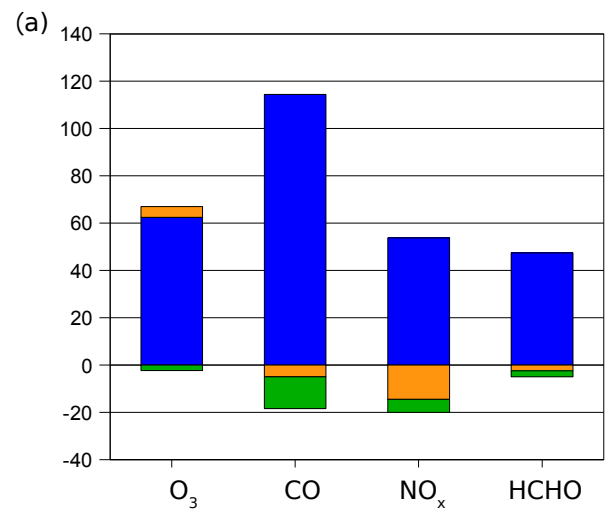

(b)

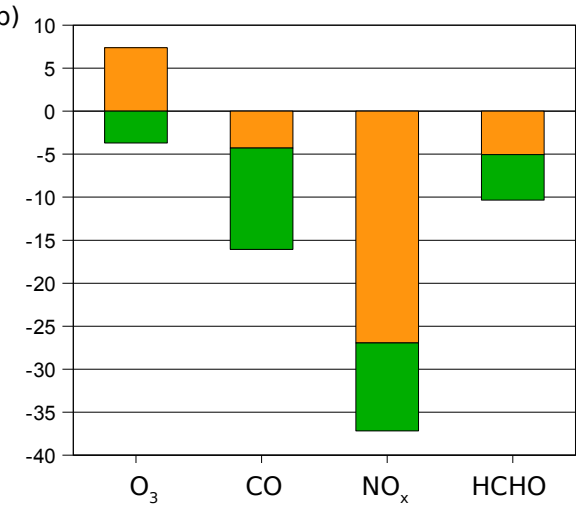

Fig. 12. Quantification of undisturbed transport (blue), chemistry (orange), and mixing (green), as outlined in the right part of Figs. 3 and 4 , is obtained from the five-day data presented in Fig. 11. Ozone $\left(\mathrm{O}_{3}\right)$ and carbon monoxide (CO) mixing ratios are given in $\mathrm{nmol} / \mathrm{mol}$ (ppbv), formaldehyde ( $\mathrm{HCHO}$ ) and the sum of nitric oxide and nitrogen dioxide mixing ratios $\left(\mathrm{NO}+\mathrm{NO}_{2}=\mathrm{NO}_{\mathrm{x}}\right)$ in $\mathrm{pmol} / \mathrm{mol}$ (pptv). Absolute contributions (a) and contributions in percent relative to the initial mixing ratios, i.e. transport (b) are shown.

selected trajectory, formaldehyde is produced from diverse intermediates of methane oxidation and is subsequently almost exclusively transformed to carbon monoxide. Carbon monoxide, in turn, is almost exclusively produced from formaldehyde and is only chemically destroyed by hydroxyl radicals.

Note that the detailed budgeting of chemistry as presented here is only applicable to chemical species which do not participate in fast-cycling reaction schemes (non-linear chemistry). Chemical source and sink terms of species involved in catalytic cycling are often huge compared to the net change in mixing ratio. Thus, the crucial reactions causing the net change are difficult to identify. They, however, govern the lifetime of such a species on a larger scale (ensemble lifetime or chemical residence time) as opposed to the immensely shorter chemical lifetime of a single molecule (burden divided by loss). Hence, for chemical systems with (a)

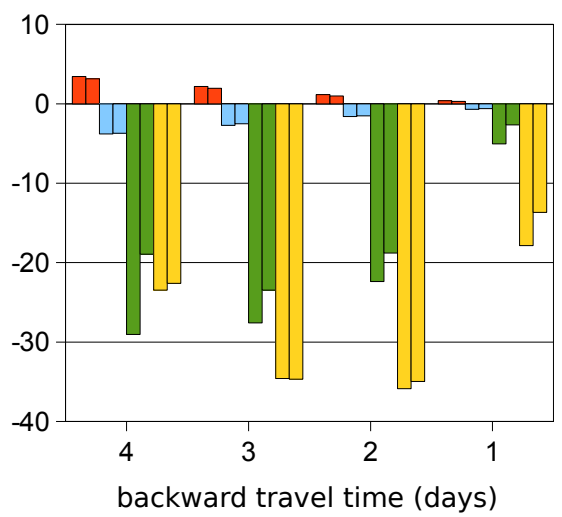

(b)

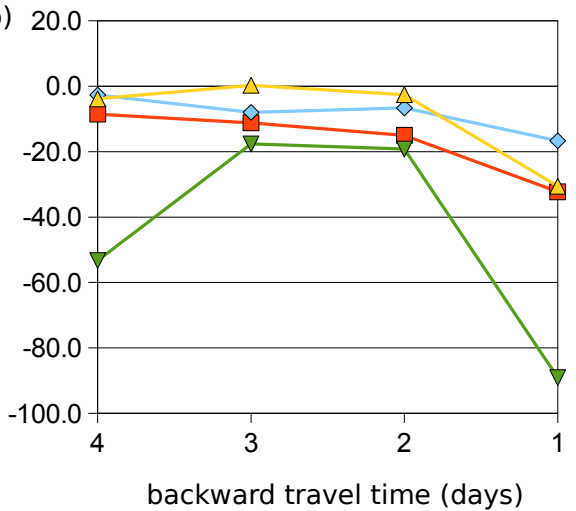

(c)

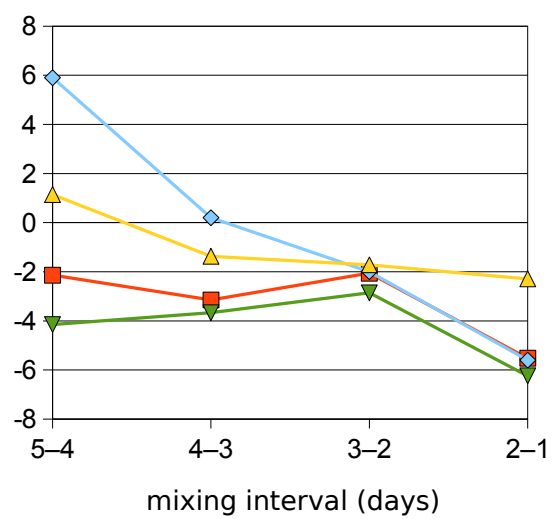

Fig. 13. (a) Chemistry contributions as mixing ratios (same units as in Fig. 12) for different trajectory backward travel times. The left column of a pair is the chemistry contribution without mixing during one whole day prior to the start of the trajectory-box model simulation; the right column shows the contribution including the chemistry contribution due to mixing. Column pairs from left to right for each backward travel time: $\mathrm{O}_{3}$ (red), $\mathrm{CO}$ (blue), $\mathrm{NO}_{\mathrm{x}}$ (green), HCHO (yellow). (b) The respective percentages of chemistry due to mixing during the day before the trajectory-box model calculation started. A negative percentage is equivalent to a negative feedback, which means a dampening of chemistry contributions through mixing. Symbols: $\mathrm{O}_{3}$ as squares, $\mathrm{CO}$ as diamonds, $\mathrm{NO}_{\mathrm{x}}$ as inverted triangles, $\mathrm{HCHO}$ as upright triangles, colors same as in (a). (c) Absolute mixing contributions during the day before the start of the chemistry calculation for the same selected tracers. Colors and symbols same as in (b), same units as in Fig. 12. 

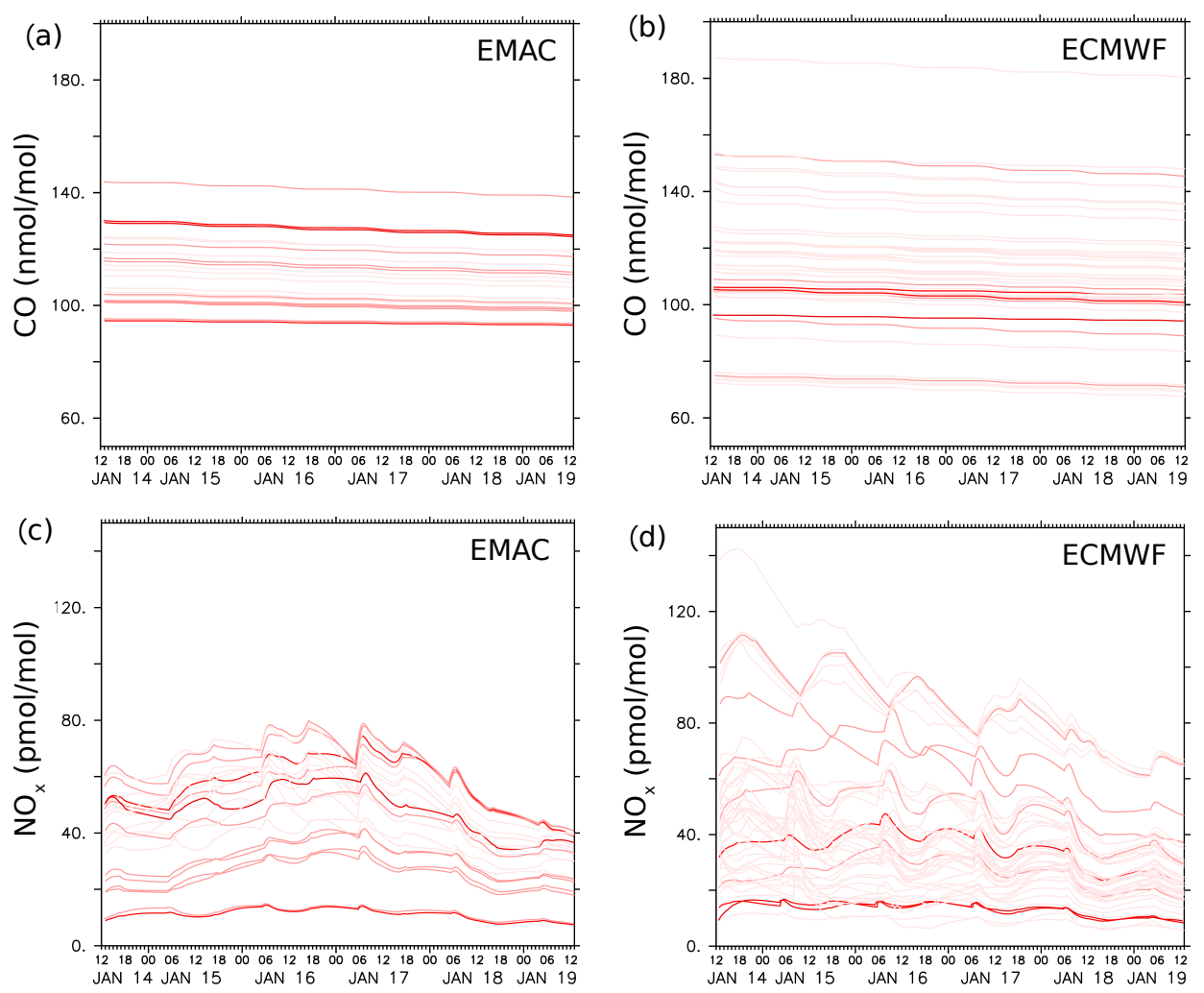

Fig. 14. Ensemble plot for carbon monoxide (a, b) and nitrogen oxides (c, d) simulated on trajectories based on EMAC (a, c) and ECMWF $(b, d)$ in the same time interval. The more intense the red hue the more statistical weight the respective trajectory has.

catalytic cycles we recommend more sophisticated budgeting methods. The method by Lehmann (2004), for instance, analyses chemical reaction pathways including chemical reaction cycles and allows to neglect the chemical contributions of these cycles. Notably, there is no need to feed preexisting knowledge into the analysis. In that way, an ensemble lifetime of a fast-cycling species like ozone is obtainable and lies in the order of months compared to the chemical lifetime in the order of hours.

\section{Discussion}

What are the advantages of the presented method compared to writing out diagnostics from the 3-D model? Diagnostics, for example concerning contributions of chemistry, can also be written out on the three-dimensional grid of the atmospheric-chemistry GCM. However, in order to analyse and integrate process contributions along atmospheric transport pathways, large amounts of data need to be produced for the complete grid since trajectories can travel once around the Earth within a few days. We would have to output the concentration tendencies for each chemical species for each process and reaction at each time step for each grid point, possibly also prolonging 3-D simulation time. Additionally, all contributions would have to be summed up following the different transport pathways in the model defined by the wind fields. The quantification method presented here achieves this separation and integration of contributions along transport pathways without having to write out large amounts of diagnostic 3-D data fields online, of which only a minute fraction would be used afterwards. Our Lagrangian method efficiently restrains the amount of 3-D data needed and uses it offline.

Two types of consistency are addressed in this publication: intra-model consistency between the trajectory-box model CAABA/MJT and the 3-D EMAC model, and consistency between the models and reality represented by observations or assimilated data (e.g., ECMWF, NCEP).

The intra-model consistency is based on three aspects: a common chemical and photochemical mechanism, trajectory-box model physical parameters consistent with the 3-D model, and consistent transport in both models. The modular MESSy software structure enables convenient sharing of a common chemistry and photochemistry mechanism between trajectory-box model and 3-D model. Consistent transport in time and space is achieved via the calculation of trajectories based on 3-D model wind fields, and the corresponding parameters are sampled from the 3-D model. Within the model hierarchy, the quantification of transport, 
(a)

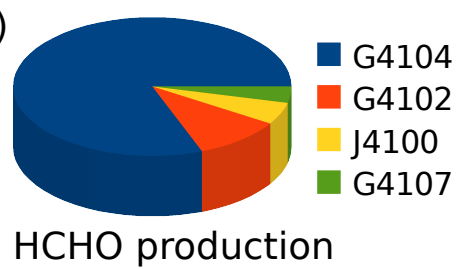

(b)

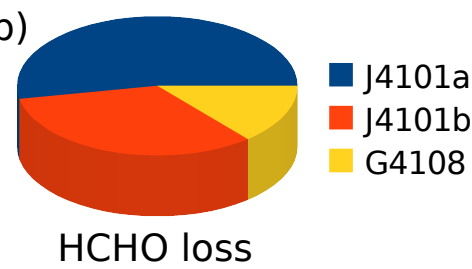

(c)

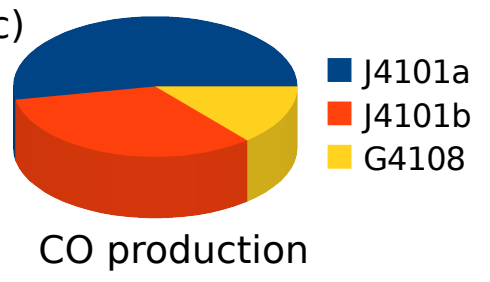

Fig. 15. Most important contributions of single reactions to the production of formaldehyde (a), loss of formaldehyde (b), and production of carbon monoxide (c). The corresponding values and chemical equations are listed in Table 3.

Table 3. Chemical production and loss reactions for formaldehyde and carbon monoxide. Turnover is given as absolute mixing ratio and as percentage of all production or of all loss for a species, respectively.

\begin{tabular}{|c|c|c|c|c|c|}
\hline & & reaction ID & $\begin{array}{r}\text { turnover } \\
(\mathrm{pmol} / \mathrm{mol})\end{array}$ & $\begin{array}{r}\text { turnover } \\
(\%)\end{array}$ & reaction \\
\hline $\mathrm{HCHO}$ & production & $\begin{array}{l}\text { G4104 } \\
\text { G4102 } \\
\text { J4100 } \\
\text { G4107 }\end{array}$ & $\begin{array}{r}1040.0 \\
133.0 \\
66.2 \\
49.7\end{array}$ & $\begin{array}{r}79.49 \\
10.10 \\
5.04 \\
3.78\end{array}$ & $\begin{array}{l}\mathrm{CH}_{3} \mathrm{O}_{2}+\mathrm{NO} \rightarrow \mathrm{HCHO}+\mathrm{NO}_{2}+\mathrm{HO}_{2} \\
\mathrm{CH}_{3} \mathrm{OH}+\mathrm{OH} \rightarrow \mathrm{HCHO}+\mathrm{HO}_{2} \\
\mathrm{CH}_{3} \mathrm{OOH}+\mathrm{h} \nu \rightarrow \mathrm{HCHO}+\mathrm{OH}+\mathrm{HO}_{2} \\
\mathrm{CH}_{3} \mathrm{OOH}+\mathrm{OH} \rightarrow .7 \mathrm{CH}_{3} \mathrm{O}_{2}+.3 \mathrm{HCHO}+.3 \mathrm{OH}+\mathrm{H}_{2} \mathrm{O}\end{array}$ \\
\hline $\mathrm{HCHO}$ & loss & $\begin{array}{l}\text { J4101a } \\
\text { J4101b } \\
\text { G4108 }\end{array}$ & $\begin{array}{l}698.00 \\
436.00 \\
182.00\end{array}$ & $\begin{array}{l}53.00 \\
33.14 \\
13.84\end{array}$ & $\begin{array}{l}\mathrm{HCHO}+\mathrm{h} v \rightarrow \mathrm{H}_{2}+\mathrm{CO} \\
\mathrm{HCHO}+\mathrm{h} v \rightarrow \mathrm{H}+\mathrm{CO}+\mathrm{HO}_{2} \\
\mathrm{HCHO}+\mathrm{OH} \rightarrow \mathrm{CO}+\mathrm{H}_{2} \mathrm{O}+\mathrm{HO}_{2}\end{array}$ \\
\hline $\mathrm{CO}$ & production & $\begin{array}{l}\text { J4101a } \\
\text { J4101b } \\
\text { G4108 }\end{array}$ & $\begin{array}{l}698.0 \\
436.0 \\
182.0\end{array}$ & $\begin{array}{l}52.36 \\
32.73 \\
13.67\end{array}$ & $\begin{array}{l}\mathrm{HCHO}+\mathrm{h} v \rightarrow \mathrm{H}_{2}+\mathrm{CO} \\
\mathrm{HCHO}+\mathrm{h} v \rightarrow \mathrm{H}+\mathrm{CO}+\mathrm{HO}_{2} \\
\mathrm{HCHO}+\mathrm{OH} \rightarrow \mathrm{CO}+\mathrm{H}_{2} \mathrm{O}+\mathrm{HO}_{2}\end{array}$ \\
\hline $\mathrm{CO}$ & loss & G4110 & 6230.00 & 100.00 & $\mathrm{CO}+\mathrm{OH} \rightarrow \mathrm{H}+\mathrm{CO}_{2}$ \\
\hline
\end{tabular}

mixing, and chemistry is always valid and can be used to study 3-D model characteristics. Using adequate models, this consistency can always be achieved. For the case study presented here, we chose to slightly reduce the intra-model consistency to simplify the sample application. For instance, photolysis rate coefficients were scaled using only one coefficient from the 3-D model. Starting from the highest consistency, the impact of such simplifications can easily be studied by trajectory-box model sensitivity simulations.

The second consistency is the basis for the transferability of the model-based analysis to observations. It is more difficult to assess and requires additional analyses. Straightforward prerequisites to be tested are the agreement of the observations with correspondingly sampled data from the 3-D model, and the comparison between trajectories based on the 3-D model wind fields and based on the forecast or reanalysis model wind fields as described in Sect. 2.5. Quantitatively, the simplest method to compare model results to observations is a point-to-point comparison. If 3-D data from observations are available or if a comparison with 3-D data from the forecast/reanalysis model is desired, advanced methods exist for the comparison of 3-D data fields, such as objectoriented comparisons avoiding double penalties when com- paring similar atmospheric patterns that are shifted in space or time (e.g., McBride and Ebert, 2000). For the basic transferability of the meteorological situation, however, we limit the analysis example here to the qualitative comparison of representative trajectories.

An interesting aspect is the exact definition of the terms transport, mixing and chemistry in this context. The definition of the contribution of transport is the most straightforward (see Sect. 2) and needs no further explanation. The contribution of chemistry is also quite intuitive as it is described by a well-defined set of chemical equations, the solution of which is only influenced by the initial state and prescribed physical parameters. The definition of the mixing term is more complex. It includes all the processes and movement of air masses inside EMAC with the exception of the transport along the trajectories, such as the mixing due to vertical and horizontal diffusion, parameterised convection, scavenging, and deposition. Furthermore, it generally also includes the effects of mixing onto chemistry, with the exception of chemically inert tracers. As such, the term "mixing" is meant in a broad context and is not to be confounded with "diffusive mixing" alone. The aforementioned secondary effects onto chemistry can become quite interesting, especially 
for species in non-linear reaction schemes as mentioned in Sect. 4.3. For very short-lived species like the hydroxyl radical $(\mathrm{OH})$, the effect of mixing onto chemistry is simply the mixing contribution itself. For very long-lived tracers like $\mathrm{SF}_{6}$, there are virtually no secondary effects in the very slow chemistry. Generally, unresolved secondary effects onto chemistry can be turned into primary effects in CAABA/MJT by reducing backward travel time as described in Sect. 2.4.

The quantification method is applied individually for each chemical species due to the specific dependence on the chemical and physical environment of each species, such as concentration gradients or sensitivity to radiation for photolysis. The quantification is available at each trajectory time step of the trajectory, but can also be condensed to net contributions considering the whole trajectory.

The trajectory-box model is not confined to back trajectories and initialisation from the 3-D model. An initialisation using observational data, for instance, is possible. For the quantification method presented here, however, the consistency with the 3-D model at the start of a trajectory simulation is essential for the quantification of mixing. The choice for forward or backward trajectories is nevertheless open depending on the intended application of the quantification method.

A general improvement of input data with respect to the quality of parameters for the trajectory simulations and of mixing ratios sampled from the 3-D model can be achieved via online sampling during the 3-D model simulation. This is implemented for satellite and airplane tracks (Jöckel et al., 2009) and could be extended to online trajectory calculations and sampling. Interpolation errors leading to artefacts in the mixing contribution and the amount of stored data are thus minimised.

\section{Summary}

The simplest approach for measurement data analysis is trying to relate, for instance, high ozone levels in the upper troposphere with backward trajectories from the stratosphere. This qualitative approach, however, does not reveal the processes during transport, i.e., chemistry and mixing. With our quantitative method, we gain additional information about contributions of various processes and where they occur.

The quantification method presented in this paper represents a new tool for the quantification of transport, chemistry, and mixing along atmospheric trajectories in a model hierarchy. A new trajectory-box model CAABA/MJT was developed, its specialty being the high consistency with respect to the 3-D global ECHAM/MESSy atmospheric-chemistry (EMAC) model. Based on this model hierarchy, the separation and quantification of transport, mixing, and chemistry along atmospheric trajectories is achieved through comparisons of results from the two models. The trajectories to be analysed are based on wind fields from the 3-D model to ensure the consistency of transport between both models.

In order to achieve a sound statistical basis for results, the trajectories are grouped into clusters, of which only the central one is used for the trajectory-box model simulations. The higher its statistical weight - the number of trajectories within the cluster - the more representative are the respective quantification results.

For the transfer of findings to observations, modelobservation agreement at the site of observation is a prerequisite. Transport differences between the nudged GCM EMAC and ECMWF analysis data are checked by comparing the respective backward trajectories.

An analysis of the spatial and temporal development of trajectory convergence or divergence is feasible by a variation of the backward travel time of trajectories. A decrease in the number of trajectory clusters formed points to a convergence of transported air masses.

The quantification method yields absolute contributions of transport, chemistry, and mixing to the mixing ratio of a species along a certain trajectory. Further analysis includes an uncertainty estimate for the contributions from transport and chemistry as well as a detailed analysis of chemical processes. It is furthermore possible to separate the chemistry contribution due to transport from the chemistry contribution due to mixing.

The method presented here is a time-efficient Lagrangian tool for offline analysis of chemistry, mixing, and transport pathways in grid-based 3-D model simulations. Under certain prerequisites, its application can help to interpret and complement measurements. Its application might thus also point to possible improvements for the 3-D model in terms of mixing or chemistry. Sensitivity simulations of chemistry with respect to the chemical mechanism or to physical parameters from the 3-D model can be implemented efficiently using the trajectory-box model. The code and a sample trajectory are included in the joint CAABA publication by Sander et al. (2009).

Acknowledgements. We would like to thank Heini Wernli (University of Mainz and ETH Zurich), who supplied the LAGRANTO back trajectories based on ECMWF reanalysis data and based on EMAC S1 data. H. Riede gratefully acknowledges the financial support rendered by the Max Planck Society and the International Max Planck Research School for Atmospheric Chemistry and Physics. The authors also wish to acknowledge use of the Ferret program for analysis and some graphics in this paper. Ferret is a product of NOAA's Pacific Marine Environmental Laboratory (http://ferret.pmel.noaa.gov/Ferret/).

The service charges for this open access publication have been covered by the Max Planck Society.

Edited by: A. Sandu 


\section{References}

Arteta, J. and Cautenet, S.: Study of ozone distribution over the south-eastern France (ESCOMPTE campaign): discrimination between ozone tendencies due to chemistry and to transport, J. Atmos. Chem., 58, 111-130, 2007.

Barbosa, P. M., Stroppiana, D., and Grégoir, J.-M.: An assessment of vegetation fire in Africa (1981-1991): Burned areas, burned biomass, and atmospheric emissions, Global Biogeochem. Cy., 13, 933-950, 1999.

Jang, J. C., Jeffries, H. E., and Tonnesen, S.: Sensitivity of ozone to model grid resolution - II. Detailed process analysis for ozone chemistry, Atmos. Environ., 29, 3101-3114.

Jöckel, P., Sander, R., Kerkweg, A., Tost, H., and Lelieveld, J.: Technical Note: The Modular Earth Submodel System (MESSy) - a new approach towards Earth System Modeling, Atmos. Chem. Phys., 5, 433-444, 2005, http://www.atmos-chem-phys.net/5/433/2005/.

Jöckel, P., Tost, H., Pozzer, A., Brühl, C., Buchholz, J., Ganzeveld, L., Hoor, P., Kerkweg, A., Lawrence, M. G., Sander, R., Steil, B., Stiller, G., Tanarhte, M., Taraborrelli, D., van Aardenne, J., and Lelieveld, J.: The atmospheric chemistry general circulation model ECHAM5/MESSy1: consistent simulation of ozone from the surface to the mesosphere, Atmos. Chem. Phys., 6, 50675104, 2006,

http://www.atmos-chem-phys.net/6/5067/2006/.

Jöckel, P., Kerkweg, A., Pozzer, A., Sander, R., and Tost, H.: Development cycle 2 of the Modular Earth Submodel System,Geosci. Model Dev. Discuss., in preparation, 2009.

Kentarchos, A. S., Roelofs, G. J., and Lelieveld, J.: Altitude distribution of tropospheric ozone over the Northern Hemisphere during 1996, simulated with a chemistry-general circulation model at two different horizontal resolutions, J. Geophys. Res., 106, 17453-17469, 2001.

Kerkweg, A., Sander, R., Tost, H., Jöckel, P., and Lelieveld, J.: Technical Note: Simulation of detailed aerosol chemistry on the global scale using MECCA-AERO, Atmos. Chem. Phys., 7, 2973-2985, 2007,

http://www.atmos-chem-phys.net/7/2973/2007/.

Knudsen, B. M., Pommereau, J.-P., Garnier, A., Nunez-Pinharanda, M., Denis, L., Letrenne, G., Durand, M., and Rosen, J. M.: Comparison of stratospheric air parcel trajectories based on different meteorological analyses, J. Geophys. Res., 106, 3415-3424, 2001.

Landgraf, J. and Crutzen, P. J.: An efficient method for online calculations of photolysis and heating rates, J. Atmos. Sci., 55, 863878, doi:10.1175/1520-0469(1998)055, 1998.

Lehmann, R.: An algorithm for the determination of all significant pathways in chemical reaction systems, J. Atmos. Chem., 47, 45-78, 2004.

Manonom, R., Xiaoen, L., and Wongwises, P.: A new LagrangianEulerian coupling model system, Adv. Atmos. Sci., 17, 587-600, 2000.

McBride, J. L. and Ebert, E. E.: Verification of quantitative precipitation forecasts from operational numerical weather prediction models over Australia, Weather Forecast., 15, 103-121, doi: 10.1175/1520-0434(2000)015, 2000.
McKenna, D. S., Konopka, P., Grooß, J.-U., Günther, G., Müller, R., Spang, R., Offermann, D., and Orsolini, Y.: A new Chemical Lagrangian Model of the Stratosphere (CLaMS) 1. Formulation of advection and mixing, J. Geophys. Res., 107, 4309, doi:10. 1029/2000JD000114, 2002.

Parrish, D. D., Stohl, A., Forster, C., Atlas, E. L., Blake, D. R., Goldan, P. D., Kuster, W. C., and de Gouw, J. A.: Effects of mixing on evolution of hydrocarbon ratios in the troposphere, J. Geophys. Res., 112, 34, doi:10.1029/2006JD007583, 2007.

Roeckner, E., Brokopf, R., Esch, M., Giorgetta, M., Hagemann, S., Kornblueh, L., Manzini, E., Schlese, U., and Schulzweida, U.: Sensitivity of simulated climate to horizontal and vertical resolution in the ECHAM5 atmosphere model, J. Climate, 19, 3771-3791, doi:10.1175/JCLI3824.1, 2006.

Sander, R., Kerkweg, A., Jöckel, P., and Lelieveld, J.: Technical note: The new comprehensive atmospheric chemistry module MECCA, Atmos. Chem. Phys., 5, 445-450, 2005, http://www.atmos-chem-phys.net/5/445/2005/.

Sander, R., Gromov, S., Harder, H., Jöckel, P., Kerkweg, A., Kubistin, D., Riede, H., Taraborrelli, D., and Xie, Z.-Q.: The atmospheric chemistry box model CAABA/MECCA-3.0, Geosci. Model Dev. Discuss., in preparation, 2009.

Sandu, A. and Sander, R.: Technical note: Simulating chemical systems in Fortran90 and Matlab with the Kinetic PreProcessor KPP-2.1, Atmos. Chem. Phys., 6, 187-195, 2006, http://www.atmos-chem-phys.net/6/187/2006/.

Scheele, M. P., Siegmund, P. C., and Velthoven, P. F. J.: Sensitivity of trajectories to data resolution and its dependence on the starting point: in or outside a tropopause fold, Meteorol. Appl., 3, 267-273, 1996.

Sinnhuber, B.-M., Müller, R., J., L., Bovensmann, H., Eyring, V., Klein, U., Trentmann, J., Burrows, J. P., and Künzi, K. F.: Interpretation of mid-stratospheric Arctic ozone measurements using a photochemical box-model, J. Atmos. Chem., 34, 281-290, 1999.

Stenke, A., Dameris, M., Grewe, V., and Garny, H.: Implications of Lagrangian transport for simulations with a coupled chemistryclimate model, Atmos. Chem. Phys., 9, 5489-5504, 2009, http://www.atmos-chem-phys.net/9/5489/2009/.

Stohl, A.: Computation, accuracy and applications of trajectories a review and bibliography, Atmos. Environ., 32, 947-966, 1998.

Stohl, A., Wotawa, G., Seibert, P., and Kromp-Kolb, H.: Interpolation errors in wind fields as a function of spatial and temporal resolution and their impact on different types of kinematic trajectories, J. Appl. Meteorol., 34, 2149-2165, doi:10.1175/ 1520-0450(1995)034, 1995.

Stohl, A., Haimberger, L., Scheele, M. P., and Wernli, H.: An intercomparison of results from three trajectory models, Meteorol. Appl., 8, 127-135, 2001.

Stohl, A., Forster, C., Frank, A., Seibert, P., and Wotawa, G.: Technical note: The Lagrangian particle dispersion model FLEXPART version 6.2, Atmos. Chem. Phys., 5, 2461-2474, 2005, http://www.atmos-chem-phys.net/5/2461/2005/.

Wernli, H. and Davies, H. C.: A Lagrangian-based analysis of extratropical cyclones. I: The method and some applications, Q. J. Roy. Meteor. Soc., 123, 467-489, doi:10.1256/smsqj.53810, 1997. 